\title{
NEWBORN INDIVIDUALIZED DEVELOPMENTAL CARE AND ASSESSMENT PROGRAM (NIDCAP) TERHADAP HASIL JANGKA PANJANG PERKEMBANGAN BAYI PREMATUR: SUATU TELAAH
}

\author{
Defi Efendi ${ }^{1,2 *}$, Yeni Rustina ${ }^{3}$
}

1. Fakultas Ilmu Kesehatan Universitas Muhammadiyah Jember, Jember 68100, Indonesia

2. Program Studi Magister Fakultas Ilmu Keperawatan Indonesia, Depok 16424, Indonesia

3. Fakultas Ilmu Keperawatan Indonesia, Depok 16424, Indonesia

*E-mail: defiefendi86@gmail.com

\begin{abstract}
Abstrak
Neonates Intensive Care Units (NICU) merupakan tempat penting untuk bayi prematur yang sekaligus merupakan tempat berbahaya akibat karakteristik NICU. NICU dapat meningkatkan risiko gangguanperkembangan bayi. Gangguan ini dapat dicegah melalui penerapan asuhan perkembangan. Newborn Individualized Developmental Care and Assessment Program (NIDCAP) merupakan metode asuhan perkembangan yang dianggap sebagai salah satu pendekatan terbaik dalam pemberian asuhan perkembangan dengan pertimbangan NIDCAP mampu memberikan pelayanan secara individual berdasarkan isyarat bayi dengan pendekatan perawatan berfokus keluarga. Pengukuran efektifitas NIDCAP didasarkan pada respon neurobehavioral bayi prematur saat berada di NICU. NIDCAP terbukti dapat memperbaiki pola tidur bayi, dan respons fisiologis bayi seperti saturasi oksigen, pernafasan, dan nadi. Hasil studi literatur menunjukkan bahwa asuhan perkembangan dengan menggunakan metode NIDCAP tidak berpengaruh terhadap hasil perkembangan bayi prematur jangka panjang. Studi dan pengkajian yang mendalam diperlukan untuk menemukan asuhan perkembangan dengan menggunakan metode yang lebih efektif dan efisien.
\end{abstract}

Kata kunci: bayi prematur, hasil jangka panjang, Newborn Individualized Developmental Care and Assessment Program (NIDCAP)

\begin{abstract}
A Review: Newborn Individualized Developmental Care and Assessment Program (NIDCAP) to Development of Long-Term Results Premature Infants. Neonatal Intensive Care Unit (NICU) is both vital spot for preterm infant and also dangerous spot which caused by NICU's characteristics. NICU increases the risk of infant developmental disturbance. Infant developmental disturbance can be prevented by implementing Developmental care in NICU setting. Newborn Individualized Developmental Care and Assessment Program (NIDCAP) is method who beingregarded as one of the best approach for delivering developmental care with those consideration NIDCAP is able to give an individual service base on the infant cues trough family-centered care approach. The measurement of NIDCAP effectiveness is shown by the infant's neurobehavioral response in the NICU. NIDCAP can repair the baby's sleep-awake pattern, and her physiological response such as oxygen saturation, respiration rater, and hearth rate. This study show that the implementation of developmental care using the NIDCAP method doesn't affect to the long-term outcome for the preterm infants. The further research is needed to find out the other developmental care method which is more effective and efficient.
\end{abstract}

Keywords: long-term outcome, Newborn Individualized Developmental Care and Assessment Program (NIDCAP), preterm infant.

\section{Pendahuluan}

Kelahiran bayi prematur memberi kontribusi yang besar terhadap angka kematian bayi baru lahir, sekitar $35 \%$ bayi yang lahir adalah prematur
(Survey Demografi dan Kesehatan Indonesia, 2012). Bayi prematur adalah bayi yang sangat rentan terhadap ketidakmampuan dalam beradaptasi dengan lingkungan ekstra uterin (Goins, 2011). Kondisi ini seringkali membutuhkan pera- 
watan intensif untuk keselamatan bayi. Unit perawatan intensif untuk bayi baru lahir disebut Neonates Intensive Care Unit (NICU).

NICU merupakan tempat penting untuk bayi prematur walaupun disi lain dapat mencederai bayi yang diakibatkan oleh karakteristik ruang NICU. NICU dapat meningkatkan risiko gangguan terhadap perkembangan bayi (Rey, dalam Einy \& Scher, 2008). Para peneliti semakin berkonsentrasi terhadap efek yang ditimbulkan oleh NICU terhadap bayi prematur beberapa dekade akhir ini dengan mengembangkan model asuhan perkembangan untuk meminimalkan risiko tersebut.

Berbagai program yang terdiri dari beberapa intervensi dini untuk bayi prematur maupun keluarga mulai diujicobakan sejak tahun 1980an (Einy \& Scher, 2008 p. 218). Salah satu contoh program tersebut adalah Developmental Supportive Care (DSC) yang didasarkan pada asumsi bahwa bayi prematur adalah partisipan aktif yang berkomunikasi melalui tingkah lakunya. Regulasi fisiologis serta perilaku mereka harus difasilitasi melalui serangkaian intervensi medis dan keperawatan. Intervensi tersebut diantaranya positioning, menilai dan mengadaptasi stimulasi sensoris, perawatan metode kanguru, nonnutritive sucking, kontrol nyeri, pengurangan faktor stress dari lingkungan, penempatan perawat khusus, dan perawatan berfokus pada keluarga (Gardener, 2002 dalam Einy \& Scher, 2008).

Beberapa tahun kemudian, kumpulan intervensi tersebut digabung dalam sebuah model asuhan perkembangan. Berbagai model yang telah dikembangkan antara lain: Newborn Individualized Developmental Care and Assessment Program (NIDCAP), Infant Behavioral Assessment and Intervention Program (IBAIP), Universal Developmental Care (UDC), Integrated Developmental Care Model (IDCM) (Altimier \& Phillips, 2013). Namun sejauh ini isu yang berkembang menganggap NIDCAP sebagai salah satu pendekatan terbaik dalam pemberian asuhan perkembangan dengan pertimbangan: NIDCAP mampu memberikan pelayanan yang individual berdasarkan isyarat bayi dengan pendekatan perawatan berfokus pada keluarga (Van der Pal, 2007). Hal ini tampak dari banyaknya rumah sakit diberbagai negara maju yang meneliti serta menggunakan NIDCAP. Namun disisi lain NIDCAP merupakan model yang membutuhkan banyak perubahan di rumah sakit mulai dari infrastruktur, keterampilan tenaga kesehatan, hingga kebijakan yang akan menghabiskan waktu serta dana yang tidak sedikit sehingga tidak akan mudah diimplementasikan.

Tujuan dari penulisan ini adalah untuk menganalisis efektivitas Newborn Individualized Developmental Care and Assessment Program (NIDCAP) terhadap hasil jangka panjang perkembangan bayi prematur.

\section{Metode}

Newborn Individualized Developmental Care and Assessment Program (NIDCAP) merupakan suatu pendekatan komprehensif yang terdiri dari metode observasi perilaku dan pembuatan asuhan perawatan perkembangan individu (VandenBerg, 2007). NIDCAP didesain untuk menciptakan dukungan terhadap perkembangan bayi yang didasarkan pada hubungan interaktif bayi dan orang tua (Kleberg, Hellström-westas, \& Widström, 2007).

NIDCAP yang disusun berdasarkan Synactive Theory yang dikembangkan Heideline Als (Sehgal \& Stack, 2006). NIDCAP terdiri dari lima subsistem meliputi autonomic/physiologic subsystem seperti denyut nadi, warna kulit, respirasi (frekuensi pernapasan dan saturasi oksigen), pencernaan, eliminasi, motoric subsystem yang berupa postur, tonus, dan pergerakan, state organizational subsystem berupa tingkat kesadaran, keadaan tidur dan terjaga (menangis), Attentional interactive berupa respon dan rentang perhatian terhadap lingkungan, self regulatory subsystem berupa kemampuan bayi untuk meregulasi diri terhadap stimulus yang datang yang bertujuan untuk mempertahankan keseimbangan atau mempertahankan stabilisasi diri (Blatz, 2001; Vandenberg, 2007). 


\section{Hasil}

Penerapan NIDCAP di NICU. Pemberian asuhan perkembangan yang bersifat individu terdiri dari upaya untuk mengembangkan koordinasi neourobehavior dan fisiologis dari sistem otonom, motorik, perhatian, serta regulasi diri pada bayi. Implementasi NIDCAP pada asuhan perkembangan tidak berfokus pada pencapaian tanda-tanda perkembangan, atau menstimulasi bayi untuk menunjukkan kemampuan khusus dari bayi, tetapi asuhan perkembangan ini merupakan upaya untuk mendukung koordinasi dan stabilisasi dari sistem otonomik, motorik pada setiap jenjang maturitas dan menurunkan tingkat stress pada bayi (VandenBerg, 2007).

NIDCAP memiliki dua rekomendasi yang dapat dipilih untuk diterapkan di NICU yaitu Basic Developmental Care dan Complete Developmental Care. Basic Developmental Care terdiri dari Standardized nest (untuk memfasilitasi positioning pada bayi) dan Standardized incubator cover (untuk mengurangi level cahaya pada inkubator (Van der Pal, 2007). Complete Developmental Care terdiri dari sistem yang sangat kompleks antara lain modifikasi lingkungan (cahaya, suara, aktifitas, suara inkubator, perasa, sentuhan, suhu ruangan, jarak antar bed, area staff perawatan), implementasi perawatan pada bayi (positioning, feeding, skin care, bathing, pengkajian nyeri, dokumentasi, pengaturan staff), implementasi perawatan berfokus pada keluarga (komunikasi dengan keluarga, dukungan keluarga, Discharge Planing, pembuatan keputusan). NIDCAP juga mengatur implementasi profesionalisme kerja antar tim seperti konsistensi perawat dan tim medis dalam pemberian pelayanan, tim perawatan yang terintegrrasi, kebijakan, serta dukungan mentorship perawat (Smith, Buehler, \& Als, 2011).

Perkembangan pada anak. Hockenberry dan Wilson (2012) membagi tahap perkembangan anak berdasarkan usia yang terdiri dari aspek perkembangan fisik, motorik kasar, motorok halus, sensoris, bahasa, dan sosialisasi-kognisi. Pada usia 0-1 bulan, bayi masih memiliki refleks primitif sangat kuat, Doll's eye reflex memudar pada akhir bulan, respons mengepal sangat kuat, mampu memutar kepala dari satu sisi kesisi yang lain saat pronasi, mengangkat kepala sejenak dari tempat tidur, namun belum memiliki kontrol kepala saat duduk. Bayi dapat mengikuti benda bergerak dengan rentang sudut leher $45^{\circ}$ dengan jarak pandang 20-25 cm, berespon terhadap suara dengan terkejut. Bayi menggunakan bahasa refleks, pandangan, dan suara rintihan sebagai alat komunikasi dengan orang disekitarnya.

Usia 2 bulan fontanel bayi menutup.Bayi mulai mampu mengangkat kepala dari tempat tidur saat ditarik pada posisi duduk, mampu mengangkat kepalanya $45^{\circ}$ saat posisi duduk. Refleks Grasp mulai menghilang. Bayi mampu mengikuti suara dengan memutar kepalanya ke salah satu sisi. Bayi masih menggunakan refleks sebagai komunikasi.

Usia 9 bulan sudah mampu duduk dengan stabil di meja, dapat menjaga kesetabilan saat kecondongan badan kedepan, namun masih belum mampu mengontrol keseimbangan saat condong kesamping. Bayi mampu menggunakan jari jempol dan telunjuk untuk menjepit benda, mulai menunjukkan tangan yang dominan, mengambil kubus, membandingkan dua kubus dengan membawa keduanya. Bayi melokalisasi suara dengan menggerakkan kepala secara diagonal dan menuju sumber suara, persepsi yang mendalam semakin bertambah, bisa mengucapkan kata sederhana seperti "no-no". Orang tua (terutama ibu) menjadi tempat bergantung anak, serta semakin bisa berkompromi dengan orang tua.

Anak usia 2 tahun sudah mulai mampu mengontrol berkemih dan buang air besar (BAB), naik tangga dengan menggunakan dua kaki pada setiap tangga, berlari, mengambil benda dengan sempurna tanpa jatuh, dan menendang bola dengan kontrol keseimbangan yang baik. Anak mampu menyusun 6 buah balok, memasukkan objek bulat kedalam lubang yang tepat, membariskan dua atau lebih balok seperti kereta api, membuka tutup, menggambar garis lurus dan lingkaran. Anak 2 tahun mampu mengucapkan 4-6 kata termasuk nama, meminta sesuatu dengan 
cara menunjukknya, dan mengerti perintah sederhana. Anak bertoleransi terhadap perpisahan dengan orang tua dalam waktu singkat, takut dengan orang asing, danmulai meniru perilaku orang tua.

\section{Penerapan NIDCAP sebagai metode asuhan perkembangan pada bayi prematur. Asuhan} perkembangan dengan menggunakan NIDCAP pada awalnya menitik beratkan pada indikator keberhasilan medis (medical outcome) jangka pendek seperti nilai saturasi oksigen, warna kulit bayi, penurunan fungsi respirasi (Jacobs, Sokol, \& Ohlson, 2002), ataupun medical outcome jangka panjang seperti retardasi mental, kehilangan pendengaran sensori-neural, serebral palsy, dan epilepsy (Alward, 2005 dalam Vandenberg 2007). Seiring dengan pengembangan dan telaah dari asuhan perkembangan ini, hasil jangka panjang mulai bergeser kearah pengkajian yang meliputi ketidakmampuan belajar, kecerdasan (IQ) yang rendah, gangguan pemusatan perhatian, integrasi motor visual, keterlambatan bahasa, dan gangguan emosional (Vandenberg, 2007).

NIDCAP telah diterapkan dan diinterpretasikan dengan berbagai metode. NIDCAP, dibanding dengan model yang lain, menekankan pada pentingnya pengkajian pada setiap bayi sebelum menentukan rencana keperawatan. Sifat asuhan yang bersifat individual ini akan sangat bergantung pada kemampuan perawat serta respon bayi sehingga pembentukan pola asuhan yang terbaik akan sulit ditemukan. Selain itu, berbagai kontroversi penelitian tentang efektifitas NIDCAP ini muncul hingga beberapa tahun terakhir, misalnya terkait efektifitas NIDCAP terhadap perkembangan anak jangka panjang (Sandie, Shelley, Polverino, \& Wocaldo, 2008).

\section{Evidence Based Practice asuhan perkembang- an dengan menggunakan metode NIDCAP di NICU. Komponen dasar NIDCAP, sama seperti halnya model asuhan perkembangan yang lain, terdiri dari beberapa intervensi. Penelitian terbaru terkait efektifitas salah satu komponen intervensi pada NIDCAP telah banyak diteliti dengan berbagai metode. Jarus, Bart, Rabinovich,}

Sadeh, dan Bloch (2011) meneliti efek posisi supinasi dan pronasi terhadap kualitas tidur dan respon perilaku bayi prematur $(\mathrm{n}=22)$. Karlson, Heineman, Sjors, Nykvist, \& Agren (2012) mempublikasikan efek perawatan skin to skin contact efektif terhadap penurunan kehilangan panas pada bayi dan dapat digunakan untuk perawatan bayi prematur dengan ventilator. Jarus, et al (2011) memberikan kesimpulan bahwa pemberian posisi pronasi efektif dibandingkan posisi supinasi dalam meningkatkan kualitas tidur dan respon perilaku bayi. Kesimpulan yang sama dihasilkan oleh penelitian Gouna, Rakza, Kuissi, Pennaforte, dan Mur (2013), namun Gouna, et al. menambahkan posisi lateral sebagai alternatifdari posisi pronasi $(n=19)$.

Selain itu, efektifitas NIDCAP secara utuh disajikan oleh beberapa peneliti. Peters, Rosychuk, Hendson, McPherson, dan Tyebkhan (2009) melakukan penelitian pada 56 bayi prematur menghasilkan kesimpulan ada pengaruh NIDCAP terhadap hasil jangka pendek dan jangka panjang meliputi penurunan gangguan perkembangan (delay). Als, et al. (2011) melakukan penelitian pada 30 bayi prematur dengan intrauterine growth restriction. Peneliti ini menyimpulkan bahwa NIDCAP berpengaruh terhadap perkembangan neurofisiologi pada usia dua minggu usia koreksi dan perkembangan pada 9 bulan usia koreksi dengan menggunakan instrumen Bayle Scales of Infant Development.

Als, et al. (2012) mempublikasikan hasil penelitiannya dengan kriteria dan jumlah sampel yang sama bahwa terdapat hubungan antara NIDCAP dan perkembangan nerurobihavior, struktur otak, dan elektrofisiologi pada 42 minggu dan 9 bulan usia koreksi. Setahun berikutnya McAnulty et al. (2013) melakukan studi korelasi antara implementasi NIDCAP terhadap perkembangan anak usia sekolah (9 tahun, random sampling dengan $\mathrm{n}=23$ ). Als, et al. (2013) menyimpulkan bahwa ada pengaruh penerapan NIDCAP terhadap perkembangan anak usia sekolah (9 tahun). Pengaruh tersebut dapat dilihat pada fungsi eksekutif otak, struktur otak, volume otak, dan funsi otak anak usia sekolah. 
Review penelitian diatas menunjukkan efektifitas NIDCAP terhadap perkembangan bayi prematur dengan berbagai indikator pencapaian terutama hasil jangka pendek. Beberapa peneliti diatas memberikan rekomendasi untuk melakukan evaluasi terhadap hasil jangka panjang dengan menggunakan sampel yang lebih besar. Penggunaan Randomized Control Trials (RCTs) sangat disarankan untuk mendapatkan data yang lebih valid (Pierat, Goubet, Peifer, \& Sizun, 2007).

Beberapa penelitian lain mencoba menjawab tantangan tersebut. Jacobs, Sokol, dan Ohlson (2002) melakukan meta-analisis data terhadap $5 \operatorname{RCT}(n=136)$ dan 3 studi kohort $(n=185)$ yang menghasilkan kesimpulan bahwa ada peningkatan neurodevelopmental hasil pada usia 9 dan 12 bulan, tetapi tidak ada perbedaan lagi setelah 2 tahun usia koreksi. Rick (2006) melakukan literature review yang menghasilkan kesimpulan bahwa NIDCAP memberikan efek terhadap perkembangan bayi prematur hingga pada usia dua tahun, efek tersebut tidak tampak lagi pada anak usia 5 tahun 6 bulan.

Setahun kemudian VanderPal (2007), melakukan penelitian dengan menggunakan RCTs terhadap 264 bayi prematur yang terbagi menjadi dua kelompok perbandingan: RCT1 $(\mathrm{n}=136) \mathrm{ke}$ lompok perlakuan Basic Developmental Care (Standardized Nest \& Cover), dan RCT2 ( $\mathrm{n}=$ 128) dengan implementasi NIDCAP. Studi yang merupakan proyek penelitian Leiden University ini menghasilkan kesimpulan bahwa kedua kelompok perlakuan (Basic Developmental Care dan NIDCAP) efektif dalam meningkatakan kualitas hidup bayi prematur (HRQoL) jangka pendek (hingga usia satu tahun), namun hasil tersebut tidak tampak pada hasil jangka panjang (5-8 tahun). Vanderpal juga meragukan penerapan NIDCAP secara meluas karena penerapan NIDCAP membutuhkan dana yang besar, dan menghabiskan waktu perawatan.

Peneliti terakhir yang menjawab pertanyaan tentang evaluasi terhadap penerapan asuhan perkembangan dengan NIDCAP adalah Ohlson (2013). Ohlson melakukan systematic review dan meta-analisis dari penelitian RCTs yang dilakukan sebelumnya. Penelitian yang dilakukan pada 627 bayi prematur menunjukkan hasil yang tidak signifikan dari penerapan asuhan perkembangan NIDCAP terhadap perkembangan neurologis anak jangka pendek maupun jangka panjang.

\section{Pembahasan}

Penerapan asuhan perkembangan dengan menggunakan metode NIDCAP memiliki efektifitas hanya jangka pendek (short term outcome) yaitu saat berada di rumah sakit berdasarkan indikator respon neurobehavior, namun tidak berpengaruh terhadap hasil jangka panjang (Jacobs, et al, 2002; Rick, 2006; VanderPal, 2007; Orton, Spttle, Anderson, \& Boyd, 2009; Ohlson, \& Jacobs, 2013).

Tujuan utama dari asuhan perkembangan adalah mengurangi risiko morbiditas akibat hospitalisasi, sehingga klien mampu melanjutkan perjalanan tumbuh kembangnya dengan baik pada usia yang akan datang (VanderPal, 2007). Oleh karena itu, keberhasilan NIDCAP yang dipublikasikan oleh beberapa penelitian diatas bukan merupakan keberhasilan yang sesungguhnya, karena indikator keberhasilan yang digunakan adalah respon neurobehavioral saat bayi berada di rumah sakit atau bebeberapa bulan setelahnya.

Efek penerapan asuhan perkembangan dengan menggunakan metode NIDCAP juga perlu dipertimbangkan. Rick (2006) mengidentifikasi penerapan NIDCAP membutuhkan perencanaan serta biaya yang besar karena harus menyiapkan serta merubah setting lingkungan, keterampilan tenaga medis dan keperawatan, serta kebijakan rumah sakit (Smith, Buehler, \& Als, 2011). Impelementasi NIDCAP juga menyita banyak waktu dan membutuhkan keterampilan perawat yang memadai (VanderPal, 2007).

Uraian diatas menunjukkan bahwa terdapat ketidakseimbangan antara pengorbanan dalam proses penerapan asuhan perkembangan dengan menggunakan metode NIDCAP dengan hasil jangka panjang pada bayi prematur. Hal ini 
berarti bahwa alternatif asuhan perkembangan dengan menggunakan metode yang lebih efektif dan efisien perlu dipertimbangkan dan dikaji lebih mendalam.

\section{Kesimpulan}

Asuhan perkembangan dengan menggunakan metode NIDCAP efektif terhadap perkembangan bayi, tetapi tidak berpengaruh terhadap hasil perkembangan anak jangka panjang. Penerapan asuhan perkembangan dengan menggunakan metode NIDCAP membutuhkan perencanaan yang rumit, menghabiskan dana yang besar, serta membutuhkan waktu yang banyak.Studi dan pengkajian yang mendalam diperlukan untuk menemukan asuhan perkembangan dengan menggunakan metode yang lebih efektif dan efisien (HW, NN).

\section{Referensi}

Als, H., Duffy, F. H., McAnulty, G. B., Fischer, C. B., Buder, S. C.,...Ringer, S. A (2011). Is the newborn individualized developmental care and assessment program (NIDCAP) effective for preterm infants with intrauterine growth restriction?,Journal of Perinatology, 31, 130-136.

Als, H., Duffy, F. H., McAnulty, G. B., Butler, S. C., Lightbody.,... Waeisenfeld, N. I. (2012). NIDCAP improves brain function and structure in preterm infants with severe intrauterine growth restriction. Journal of Perinatology, 32, 797-803.

Altimier, L., \& Phillips, R. M. (2013). Newborn \& Infant Nursing Reviews The Neonatal Integrative Developmental Care Model: Seven Neuroprotective Core Measures for Family-Centered Developmental Care. Newborn \& Infant Nursing Reviews, 13, 9-22.

Badan Pusat Statistik, Kementrian Kesehatan Indonesia, \& USAID.(2012). Survey demografi dan kesehatan Indonesia.Jakarta: BPS (Tidak ada dalam citasi text).

Blatz, S. (2001). Experimental study of incubator covers in the neonatal ICU: Testing of a mid- range theory for newborn infants. Dissertation. Michigan: Wayne State University.

Einy, O. A., \& Scher, A. (2008). Measuring developmentally appropiate practice in neonatal intensive care units. Journal of Perinatology, $28,218-225$.

Goins, M. (2011). Developmental care: Helping premature babies thrive. Pediatrics for Parents, $27,1-2$.

Gouna, G., Rakza, T., Kussi, E., Pennaforte, T., \& Mur, S. (2013). Positioning effects on lung function and breathing patternin premature newborns. The Journal of Pediatrics, 22, 3470-3476

Jacobs, S. E., Sokol, J., Ohlsson, A. (2002). The newborn individualized developmental care and assessment program is not supported by meta-analyses of the data. The Journal of pediatrics, 2 (21), 0022-3476.

Jarus, T., Bart, O., Rabinovic, G., Sadeh, A., Bloch, L.(2011).Effects of prone and supine positions on sleep state and stressresponses in preterm infants. Infant Behavior and Development, 34 (4), 257-263.

Karlson, V., Heineman, A.-B., Sjors, G., Nykvist, K. H., \& Agren, J. (2012). Early Skin-to-Skin Care in Extremely Preterm Infants: Thermal Balance and Care Environment. The Journal of Pediatrics, 161 (3), 422-426.

Kleberg, A., Hellström-westas, L., \& Widström, A. (2007). Mothers ' perception of Newborn Individualized Developmental Care and Assessment Program (NIDCAP) as compared to conventional care. Early Human Development, 83, 403-411. doi:10.1016/j.earlhumdev.2n00 6.05 .024

McAnulty, G., Duffy, F. H., Kosta, S., Weisenfeld, N. I., Warfeld, S. K .,... Als, H. (2013). School-age effects of the newborn individualized developmental care and assessment program for preterm infants with intrauterine growth restriction: Preliminary findings. BMC Pediatrics, 13 (2), 165-173.

Ohlsson, A., Jacob, S. E. (2013). NIDCAP: Asystematic review and meta-analyses of random- 
ized controlled trials. Pediatrics, 131 (3), 881-893.

Orton, J., Spttle, A., Anderson, P., \& Boyd, R. (2009). Do early intervention programmes improve cognitive and motor outcomes for preterm infants after discharge? A sytematic review. Developmental Medicine \& Child Neurologi, 51 (11).

Pierat, V., Goubet, N., Peifer, K., Sizun, J. (2007). How can we evaluate developmental care practicesprior to their implementation in a neonatal intensivecare unit?.Early Human Development, 83 (4), 415-418.

Rick, S. L. (2006). Developmental care on newborn intensivecare units: Nurses' experiences and neuro developmental, behavioural, and parenting outcomes, a critical review of the literature. Journal of Neonatal Nursing, 12 (5), 101-112.

Sandie, B., Shelley, R., Polverino, J., \& Wocaldo, C. (2008). Implementation and Evaluation of an Individualized Developmental Care Program in a Neonatala intensive care unit. Journal for
Specialist in Pediatric Nursing, 13 (4), 281292.

Sehgal, A., \& Stack, J. (2006). Developmentally Supportive Care and NIDCAP. Indian Journal of Pediatrics, 73 (11), 57-60.

Smith, K., Buehler, D., \&Als, H. (2013). NIDCAP nursery certification program (NNCP). Boston: NIDCAP Federation International.

VandenBerg, K. A. (2007). Individualized developmental care for high risknewborns in the NICU: A practice guideline. Early Human Development, 7 (83), 433-422.

VanderPal, S. M. (2007). The Leiden developmental care project: Effects of develomental care on behavior and quality of live of very preterm infants and parental and staff experiences. Gobren te Leidschendam: Leiden University Press.

Wilson, D., \& Hockenberrry, M. J. (2012).Wong's clinical manual of pediatric nursing. Missoury: Elsevier Mosby. 